Revista de la red interuniversitaria de estudios sobre las literaturas rioplatenses contemporáneas en Francia

19 | 2018

La rebelión de los hijos: el judaísmo en la literatura latinoamericana contemporánea entre tradición y asimilación

\title{
Tipología de la modernidad judía
}

\section{Stéphane Mosès}

Traductor: Valentina Litvan

\section{(2) OpenEdition}

\section{Journals}

Edición electrónica

URL: http://journals.openedition.org/lirico/6854

DOI: $10.4000 /$ lirico.6854

ISSN: 2262-8339

\section{Editor}

Réseau interuniversitaire d'étude des littératures contemporaines du Río de la Plata

\section{Referencia electrónica}

Stéphane Mosès, «Tipología de la modernidad judía », Cuadernos LIRICO [En línea], 19 | 2018, Puesto en línea el 28 enero 2019, consultado el 21 abril 2019. URL : http://journals.openedition.org/lirico/6854 ; DOI : 10.4000/lirico.6854

Este documento fue generado automáticamente el 21 abril 2019.

\section{c) (i) $\odot$

Cuadernos LIRICO está distribuido bajo una Licencia Creative Commons Atribución-NoComercialSinDerivar 4.0 Internacional. 


\title{
Tipología de la modernidad judía
}

\author{
Stéphane Mosès \\ Tradución : Valentina Litvan
}

\section{NOTA DEL EDITOR}

En nombre de Cuadernos LIRICO agradezco a Michel Valensi y a la señora Mosès-Klapisch por haberme acordado el derecho a traducir el texto al español para esta publicación. Procedencia: “Typologie de la modernité juive", Temps de la Bible, París, Éditions de l'Éclat, 2011, p. 141-156. La traducción de las citas entre comillas son de la traductora. Las notas o comentarios de la traducción irán entre corchetes.

\section{I}

En su libro Más allá del versículo (1982), Emmanuel Levinas define su método de lectura de las fuentes judías del siguiente modo: "El significado del significante (...) solo responde al espíritu que lo solicita, que pertenece de este modo al proceso de la significación; (...) la interpretación comporta esencialmente esta solicitación sin la que lo no-dicho, inherente a la textura del enunciado, desaparecería bajo el peso de los textos y se estancaría en las letras." "Solicitar al texto significa para Levinas tanto invocarlo, requerirlo, como sobreinterpretarlo, sobrecargarlo de sentido. Este modo de ir más allá del sentido manifiesto, esta búsqueda sin fin de todos los significados que el texto pudiera encubrir cuyo sentido manifiesto es solo una de las modalidades- ha caracterizado siempre al método de interpretación rabínica de los textos canónicos. Habría, al parecer, una libertad de interpretación casi ilimitada, libertad que Gershom Scholem calificaba incluso de infinita. Aunque en realidad esta libertad -por extensa que fuera- nunca fue absoluta. En esencia, siempre estuvo limitada por un principio igualmente fundamental, el de la autoridad de la tradición. Se trata menos de una autoridad exterior, institucional y coercitiva, que de un marco conceptual o, más bien, de un horizonte de significado interior a la tradición misma. Este horizonte no reenvía a un catálogo de temas, de tesis, y 
mucho menos de dogmas, sino a un cierto arte de formular preguntas. En otros términos, lo que se transmite de generación en generación es menos un conjunto de respuestas que un campo de interrogaciones. Es este campo de interrogaciones el que confiere a la tradición su aparente continuidad y legitimidad constitutivas. De este modo, la solicitación del texto planteada por Levinas implica, por tanto, dos presupuestos aparentemente contradictorios. Uno, postula que el texto bíblico es susceptible de un gran número de interpretaciones diferentes, el otro, que el número de estas interpretaciones no es ilimitado. Así se afirman a la vez la plasticidad esencial de las Escrituras y la autoridad de la tradición que fija de una vez por todas el marco de trabajo interpretativo.

2 ¿Cuál es la parte fijada por la tradición y cuál la parte de libertad dejada al intérprete en la exégesis de un texto canónico? Para Levinas está claro que la tradición dicta el método por el que se esclarece la coherencia interna del texto, las preguntas a las que responde y las que deja abiertas, pero sobre todo el sentido que vehicula. En cuanto al intérprete, se trata de traducir la forma discursiva propia de los textos antiguos en un lenguaje comprensible para los hombres de hoy. Para Levinas, este lenguaje no es sino el discurso filosófico de la modernidad. Pero este mismo discurso es el heredero de toda la tradición filosófica occidental; a través de esta pauta de lectura los textos fundadores del judaísmo revelan su sentido universal. "Traducir al griego la sabiduría del Talmud", decía Levinas; para él, los relatos bíblicos, tanto como el desorden aparente de los textos talmúdicos, no pueden dar testimonio del pensamiento arcaico e irracional: en realidad, bajo estas formas de discurso que se han vuelto extranjeras para nosotros, se esconde un sentido universal, cuya racionalidad específica hay que sacar a la luz. "De ningún modo, escribe Levinas, este lenguaje 'exótico' o 'caduco' debe detener al pensamiento por cuanto conlleva de pintoresco (...). Este mundo consagrado o perdido en los signos se ilumina por el pensamiento que le llega desde afuera o desde el otro extremo del canon, revelando sus posibilidades a la espera de la exégesis." ${ }^{2}$ Entonces, lo que la interpretación renueva no es de ningún modo el sentido del texto, ya que este está fijado por la tradición, sino su forma, su lenguaje. El discurso filosófico vuelve visible e inteligible el sentido universal de estos textos que las formas de discursos arcaicos habían ocultado.

Esta relación interpretativa de los textos canónicos es característica de cierto aspecto de la modernidad judía que me gustaría llamar la modernidad normativa, en oposición a otra forma de modernidad que calificaré de modernidad crítica. La genealogía de esta modernidad normativa se inicia con Hermann Cohen y su obra La religión de la razón desde las fuentes del judaísmo (1914), continúa con La Estrella de la Redención de Franz Rosenzweig (1921) y conduce en línea casi directa (a través de la influencia decisiva de Jacob Gordon y de su enseñanza clandestina en el marco de la Resistencia judía) a la renovación del pensamiento judío en Francia en los años cincuenta del siglo pasado. Desde el punto de vista político y social, esta forma de modernidad nació a principios del siglo $\mathrm{XX}$, como reacción al movimiento de asimilación de los Judíos europeos durante el siglo precedente. Pero, desde el punto de vista ideológico, surgió como oposición al positivismo histórico que había marcado la Wissenschaft des Judentums (la "ciencia del judaísmo"). Dicha ciencia aplicaba a los textos canónicos de la literatura judía un método estrictamente históricofilológico, buscando determinar lo más exactamente posible sus orígenes históricos y establecer el texto a partir de un análisis riguroso de las fuentes y de los manuscritos. Para los grandes representantes de la modernidad normativa se trata, al contrario, de descifrar el significado que los textos pueden tener para un lector moderno. Su método de 
lectura, de naturaleza esencialmente hermenéutica, pone en primer plano la interacción entre el texto y su intérprete. Del mismo modo que Heidegger, Gadamer y Ricoeur, despliegan un método de lectura donde la subjetividad es inherente a todo acto interpretativo. Lo importante aquí es, ante todo, la actualización del sentido que el texto implica. Comprender un texto querrá decir entonces traducirlo al lenguaje que hablamos, el de nuestras normas, nuestras referencias culturales y nuestras preocupaciones.

Para alcanzar el sentido que tiene hoy para nosotros, tendríamos que saber de antemano, en cierto modo, su significado: es el famoso "círculo hermenéutico" sobre el que Heidegger pudo decir que pertenecía a la estructura misma del sentido ${ }^{3}$.

Lo que cabe destacar de este método hermenéutico es que, para actualizar el sentido de los textos, renueva la forma al tiempo que conserva el contenido. Para Levinas, como para Hermann Cohen y Rosenzweig antes que él, no se trata de cambiar las enseñanzas fundadoras de la tradición, sino sus modos de expresión, de transponer el discurso propio de los textos canónicos a un lenguaje inteligible para los hombres de hoy. Es por ello que esta forma de modernidad es esencialmente normativa. Los textos citados en La religión de la razón, en La Estrella de la Redención y en las Lecturas talmúdicas, e incluso en Totalidad e infinito o en De otro modo que ser, conservan su estatuto original de instancias de la verdad. Es cierto que estas citas, en tanto que tales, no bastan para legitimar el desarrollo de la argumentación, como ocurría con los tratados teológicos de la Edad Media. En Cohen, Rosenzweig y Levinas, el discurso filosófico posee su evidencia propia y -para retomar una fórmula del propio Levinas- "las citas solo sirven como ilustraciones". Pero, aunque la función de las fuentes antiguas solo sea confirmar a posteriori la precisión de los enunciados propiamente filosóficos, de ellas emana un aura fundada en la autoridad que les confiere el autor. En realidad, las citas están dotadas de una fuerza argumentativa comparable a la del propio razonamiento filosófico. En Religión de la razón o en La Estrella de la Redención, los análisis propiamente filosóficos y las citas de fuentes tradicionales se apoyan constantemente unos en otros, de manera que su estatuto epistemológico resulta casi equivalente.

Para autores como Hermann Cohen, Rosezweig o Levinas, tanto como para sus sucesores, los textos clásicos de la tradición no son solo documentos históricos o literarios que se limitarían a testimoniar para su época, sino que además son elementos de un canon que expresan una verdad válida para todos los tiempos. Frente a las ideas y a las representaciones que estos vehiculan, el intérprete "normativo" no se mantiene neutro: ve en ellas una enseñanza a la que se sigue refiriendo. Lo que define esta enseñanza es precisamente su identificación con la tradición que estudia. Pensando sobre ella, entiende preservarla y perpetuarla. Incluso cuando la reformula en lenguaje moderno, no cuestiona su verdad; sigue comprometido con ella.

\section{II}

7 En oposición a este intento de adaptar los contenidos tradicionales del judaísmo al discurso filosófico de la modernidad, vemos aparecer en el siglo XX una forma absolutamente diferente de modernidad judía, encarnada por figuras tan emblemáticas como Kafka, Walter Benjamin, Hannah Arendt y, después de la Segunda Guerra mundial, por poetas como Paul Celan o Edmond Jabès. Lo que tienen en común estos autores tan distintos entre sí es su convicción de que los contenidos de la tradición judía han perdido hoy su validez, pero que algunas de sus formas -fragmentos de textos, categorías de 
pensamiento, modos de razonamiento o de sensibilidad- todavía subsisten como restos dispersos en nuestro mundo sin Dios. Hannah Arendt dio cuenta de esta visión crítica de la modernidad en un pasaje de su ensayo "¿Dónde estamos cuando pensamos?" : "El hilo de la tradición está roto", escribe tomando una fórmula de Alexis de Tocqueville, "y no podremos restituirlo (...). Lo que se ha perdido es la continuidad con el pasado, tal y como parecían transmitírsela las sucesivas generaciones, generando su cohesión interna. (...). Nos encontramos así con el pasado, pero con un pasado fragmentario, que ya no podemos evaluar con certeza". ${ }^{4}$ Hannah Arendt define aquí la modernidad como un tiempo en el que la tradición no puede alcanzarnos. Esto es así, ante todo, porque el proceso de la transmisión se ha detenido sin remedio. Hannah Arendt se refiere aquí a la experiencia de las generaciones judías de principios del siglo XX que solo habían recibido de sus padres, ya ampliamente asimilados, esa "nada de judaísmo" de la que habla Kafka en su "Carta al padre", donde dice cruelmente que no era "verdaderamente nada, un juego, no, ni siquiera un juego"5. Por su parte, Walter Benjamin, habló a este respecto de una "enfermedad de la tradición"6. En el ensayo que le dedicó en 1968, Hannah Arendt describe con precisión la naturaleza de esta enfermedad: "Ya no podíamos volver atrás (... ). El pasado solo hablaba a través de las cosas que no se podían transmitir y cuya aparente actualidad solo se debía a su carácter exótico, de modo que no se podía esperar compromiso alguno hacia ellas". ${ }^{7}$ Estas "cosas exóticas (...) que no podían transmitirse y de las que no se podía esperar compromiso alguno" designan aparentemente a la Cábala, a la que Hannah Arendt ya se había referido unas líneas antes en el mismo texto, a propósito de "la extraña decisión de Gershom Scholem de abordar el judaísmo a través del prisma de la Cábala". Hay que entender que lo que choca a Hannah Arendt de la actitud de Scholem no es su elección de la Cábala como objeto de estudio, sino el hecho de que para ella la tradición mística judía no es en absoluto capaz de ayudar al hombre moderno en las decisiones concretas -éticas y ante todo políticas- a las que se ve confrontado. Ahora bien, a su modo de ver, la vocación moral del hombre, en tanto que ser esencialmente político, se expresa precisamente en los juicios concretos a los que se ve abocado a adoptar y en nombre de los que tendrá que actuar. Desde un punto de vista diametralmente opuesto al de Rosenzweig o Levinas, considera que las fuentes antiguas tradicionales se han vuelto anacrónicas, y que acordarles una importancia primordial solo puede desviar de su auténtica responsabilidad a quienes están comprometidos con los torbellinos de la historia.

\section{III}

8 ¿Tiene todavía actualidad la tradición judía en el mundo moderno? Treinta años antes, esta misma pregunta constituía el centro de un largo debate epistolar entre Walter Benjamin y Gershom Scholem acerca del significado de la obra de Kafka. Durante el verano de 1934, Benjamin, refugiado entonces en París, había enviado a su amigo Scholem, que desde 1923 vivía en Jerusalem, una primera versión de un estudio sobre Kafka destinado a ser publicado en Alemania en la revista Die jüdische Rundschau. En su ensayo, Benjamin interpretaba la aparición recurrente en Kafka de personajes estudiantes como un reenvío al tema de la Escritura y de su interpretación: "Sus estudiantes, decía, son discípulos que han perdido la Escritura". ${ }^{8}$ Para él, simbolizaban al hombre de la modernidad, abocado a un mundo completamente secularizado, y para quien la tradición religiosa (representada por las Escrituras) ha perdido todo significado. Es cierto que 
Scholem también pensaba que la tradición se había vuelto inaudible y que, en un mundo totalmente secularizado, ya nadie era capaz de comprender verdaderamente los textos en los que ésta se expresaba. Pero, a diferencia de Benjamin (y sin duda de Hannah Arendt), no creía que esta crisis de la tradición fuera irreversible. Si se ha vuelto ininteligible para nosotros es, pensaba, porque ya no somos capaces de descodificarla. De hecho, para Scholem, la tradición judía, y sobre todo sus textos místicos, reenvían a experiencias de naturaleza mítica que ya no somos capaces de comprender hoy. Pero nada asegura que en un futuro no vuelva a recobrar significado. Por eso responde a Benjamin que a su parecer, los estudiantes de las novelas de Kafka son representativos no de una época que ha perdido la Escritura, sino de una generación que ya no sabe descifrarla. Esta diferencia es decisiva, pues consiste en saber si la desaparición de la tradición es irreversible, como pensaba Benjamin, o si podrá despertarse un día y volver a interpelarnos. Scholem creía que la tradición judía, que desde la Biblia hasta el Talmud pasando por la Cábala y el Hassidismo había sufrido una serie de metáforas radicales, contaba con una capacidad de renovación casi ilimitada. En este sentido, Scholem se encuentra en el seno mismo de la tensión entre modernidad normativa y modernidad crítica.

9 Para abordar más de cerca el estatuto ambivalente de la tradición en un mundo "del que Dios se ha retirado", Scholem había forjado la noción de "Nada de la Revelación". A Benjamin, quien le había preguntado por el sentido de esta formulación, le había contestado: "Entiendo por ello un estado en el que la Revelación aparece vacía de significado, en el que logra imponerse, prevalece, pero en el que no significa". 9

10 Ahora bien, para Scholem la noción teológica de Revelación se manifiesta en los textos de la tradición religiosa. Podemos comprender entonces que la noción de "Nada de la Revelación" designa para él el estadio histórico en el que nos encontramos, donde el significado original de estos textos se nos escapa, pero en el que las nociones religiosas y los valores morales vehiculados siguen presentes en nuestra civilización y, en cierta medida, determinan sus normas. Como vemos, este análisis es rigurosamente contrario al de Hannah Arendt, para quien la tradición religiosa ha perdido toda validez en la esfera ética, incluso si mantiene tal vez cierto interés histórico.

11 Benjamin, que a diferencia de Scholem no creía que la tradición judía pudiera seguir siendo pertinente hoy, pensaba, sin embargo, que su mismo reflujo podía sacar a la luz fragmentos de modos de pensamiento muy antiguos o de discursos que todavía podían ser utilizados en nuestra época. Es cierto que las creencias transmitidas se habían vuelto caducas, pero algunas de las formas a través de las que se habían expresado podían retomarse y ser repensadas en contextos nuevos. Esta forma de "salvar" los restos de una tradición que había estallado (a la que ya había aludido en su texto sobre "La tarea del traductor") es característica de las últimas obras de Benjamin. En una carta de 1938 a Gershom Scholem, dedicada nuevamente a una reflexión sobre la obra de Kafka, evoca la manera como este "renunció a la verdad para conservar su transmisibilidad" ${ }^{10}$. En una época donde ya no se puede creer en la verdad de la tradición, la única manera de salvar su memoria es relatando -como Kafka en El castillo- la historia de su desaparición. En la obra de Kafka, añade Benjamin, "ya no se trata de sabiduría". Solo subsisten "los productos de su descomposición" y, ante todo, en lugar de exponer la verdad, aparece "el rumor de cosas verdaderas (una suerte de chismorreo teológico que trata sobre cosas caducas y desfasadas)" ${ }^{\prime 11}$. Para Benjamin, esta es la situación de la tradición religiosa en un mundo para el que las experiencias colectivas de las que habla y las nociones con las que se traducen han perdido todo significado. "Rumor de cosas verdaderas", "chismorreo 
teológico": rara vez los límites de un pensamiento religioso apartado de su horizonte original habrán sido desenmascarados con tan implacable lucidez.

\section{IV}

¿Cómo pueden, sin embargo, utilizarse estos "productos de descomposición" de la tradición? La respuesta sugerida por Benjamin arroja una luz significativa sobre lo que he llamado "modernidad crítica". De hecho, en su carta a Scholem distingue entre el contenido de verdad de la tradición y su transmisibilidad. La obra de Kafka, abierta a un número ilimitado de interpretaciones, sería testigo de la desaparición de la "consistencia de la verdad", es decir, de una verdad única y homogénea; pero, renunciando a la verdad, Kafka habría buscado salvar su transmisibilidad. En El castillo, por ejemplo, es precisamente la imposibilidad de acceder a una verdad clara y convincente lo que permite la multiplicación de relatos, cada vez parciales y a menudo contradictorios, sobre la naturaleza de este lugar a la vez próximo e inaccesible. Pero para poder afirmar que hoy la sustancia de la verdad se ha perdido, en primer lugar es necesario saber, aunque sea de manera intuitiva, en qué consistía. La naturaleza de esta consistencia perdida es lo que Benjamin había intentado encontrar en algunos de su textos de los años treinta. Así, en un corto fragmento narrativo titulado "Hacia el planetario", evocaba una "experiencia colectiva", que habría caracterizado la manera de percibir la realidad en la época precientífica -percepción análoga, en muchos sentidos, a la inducida por la droga-, que se habría perdido a lo largo de la evolución filogenética de la humanidad. En un texto algo posterior, "Sobre la facultad mimética", define esta "experiencia cósmica" como la facultad de percibir correspondencias y analogías en la realidad. Pero incluso después de que hubiera desaparecido esta facultad, subsistieron algunas huellas en un dominio muy particular, el del lenguaje y la escritura. Según Benjamin, estas huellas constituyen "archivos de analogías inmateriales". Así es como algunas correspondencias cósmicas pueden reaparecer fugazmente en el curso de la experiencia profana de la lectura. La "lectura profana" logra, en cierta medida, "salvar" fragmentos de experiencias cósmicas desaparecidas y hacerlas revivir en nuestra civilización "post aurática", al tiempo que "liquida sus connotaciones mágicas". Benjamin creía encontrar en Proust estas huellas de "analogías inmateriales" que recuerdan todavía la experiencia cósmica desaparecida. En los relatos de Kafka, en cambio, nada de ello subsiste; Benjamin no descubre en ellos más que este "rumor de las cosas verdaderas" que solo designa la ausencia irrevocable de una verdad inalcanzable. En ello, la lectura de estos relatos simboliza para Benjamin la situación en la que la tradición se encuentra hoy. En una época en que las experiencias transmitidas por los textos canónicos del judaísmo se han vuelto ininteligibles para nosotros, la única manera de evocarlos es describiendo las figuras de su ausencia. Midrashim modernos, los textos de Kafka están construidos como parábolas detrás de las cuales no se esconde ninguna enseñanza. Incluso, más allá de las novelas, que ponen en escena al protagonista en busca de un sentido que no cesa de escapársele, muchos relatos breves retoman un tema tradicional tomado de la mitología griega, pero que, a fuerza de analizarlo, interrogarlo, ponerlo en duda, acaban por subvertir de arriba abajo su sentido original. (En "Poseidón", el dios del mar en la mitología griega se ha convertido en un empleado de la Compañía de aguas; en "El nuevo abogado", Bucéfalo, el corcel mítico del rey Alejandro, se ha transformado en un oscuro miembro de los tribunales; en "El silencio de las sirenas", Ulises, el más astuto de los hombres, aparece como un ser inocente que 
solo encuentra su salvación gracias a su ingenuidad.) Del mismo modo, Kafka dedicó una serie de aforismos a temas bíblicos en los que trastoca irónicamente el significado. (Por ejemplo: "Si lo que fue destruido en el Paraíso era destructible, entonces no era algo importante; pero si se trataba de algo indestructible, entonces vivimos en una falsa creencia"). Benjamin, por su parte, se reapropió de nociones teológicas judías, como "Revelación", "Redención", e incluso del término "Mesías", para conferirles un sentido enteramente nuevo. Mientras que Edmond Jabès, en los años sesenta, hizo suya la forma de los discursos talmúdicos poniendo en escena una galería de rabinos imaginarios que debaten sin fin sobre el vacío desesperante de nuestro mundo, del que Dios se ha ausentado sin esperanza de retorno. Cómo no evocar, en este contexto, las tres primeras estrofas del poema "Salmo" de Paul Celan, en el que retoma sucesivamente un versículo del Génesis y su lectura tradicional, una fórmula litúrgica judía y uno de los trece artículos de fe de Maimónides, para invertir su sentido teológico original:

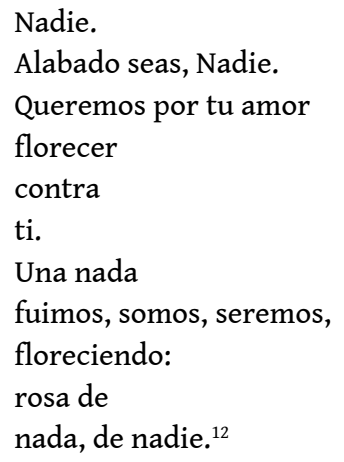

\section{V}

Cuando Kafka, Benjamin, Jabès o Celan se refieren a motivos judíos muy antiguos, no es entonces para traducirlos a un lenguaje contemporáneo y conferirles así una nueva legitimidad, sino, al contrario, para utilizarlos como puro signo. Por oposición al gesto hermenéutico de la atribución de sentido, que define a la modernidad normativa, la modernidad crítica se afirma en la revocación de significados percibidos como caducos; pero, por otro lado, las formas en las que la tradición se expresaba, y que la modernidad normativa considera como anticuadas y superadas, son precisamente retomadas por la modernidad crítica, que las integra en su propio discurso. Al pathos de la actualización de sentido, gesto fundador de la modernidad normativa, la modernidad crítica opone el "reciclaje" subversivo de las formas antiguas.

En este sentido, la diferencia entre estas dos formas de modernidad judía se manifiesta de manera evidente en la naturaleza de su relación con el texto. En la medida en que la tradición se presenta como un conjunto de textos, que consisten a su vez en un número casi ilimitado de signos, la modernidad crítica postula -contrariamente a la modernidad normativa- que este conjunto ha perdido para nosotros su coherencia interna, que los textos y los signos que lo componen no reenvían a un mismo horizonte de sentido que los unifique, en definitiva, que ha dejado de constituir un canon. Por eso la tradición aparece ante la modernidad crítica como un vasto paisaje esparcido de ruinas y de restos (a la manera de los cuadros del campo romano pintados por Nicolas Poussin), pero del que todavía se pueden reutilizar algunos fragmentos. En el discurso de la modernidad crítica, 
estos fragmentos adquieren la forma de citas. La función clásica de la cita, que consiste en garantizar y legitimar opiniones, había sido retomada en el siglo XX por los autores de la modernidad normativa. Benjamin pensaba, al contrario, que para nosotros, modernos, se trata de "actualizar en la cita no su poder de conservación, sino su poder de purificación, su aptitud para desestructurar el contexto, en otras palabras su fuerza destructiva; puesto que arrancarlas del contexto es la única esperanza de que sobrevivan algunas cosas en nuestro tiempo". ${ }^{13}$

\section{VI}

A partir de este pasaje de Benjamin, la oposición entre modernidad normativa y crítica cobra una nueva luz. Recupera, en cierto sentido, la oposición instituida por Gershom Scholem entre restauración y utopía. La vocación de la modernidad normativa es redescubrir verdades religiosas originales, tal y como se expresan en los textos canónicos de la tradición, y traducirlas a un lenguaje adaptado a los problemas de nuestro tiempo. Esta reformulación (que es también una repetición) de verdades inmutables está destinada a confirmar y reafirmar las raíces del hombre moderno en su tradición. Pero podemos preguntarnos si esta actitud fundamentalmente conservadora no limita la aptitud de la modernidad normativa para descubrir, en los textos tradicionales, significados revolucionarios que también esconden. A diferencia de determinadas exégesis rabínicas que no dudan en subvertir radicalmente el sentido aparente de los textos que comentan, esta ofrece en cambio una continuidad, pero pocas esperanzas. La esperanza solo se encontraría tal vez para nosotros en el descubrimiento fulgurante de lo inesperado. Solo la revelación repentina de posibilidades desconocidas hasta ahora, entre los restos de una tradición que ha estallado en pedazos, nos permitiría reencontrar en ese pasado el resplandor de una esperanza.

\section{NOTAS}

1. Emmanuel Levinas, L'Au-Delà du verset, Paris, Editions de Minuit, 1982, p. 136.

Reproduzco las referencias francesas utilizadas por Mosès y traduzco directamente las citas a partir de su texto.

2. Emmanuel Levinas, op. cit., p. 127.

3. Martin Heidegger, Sein und Zeit, Tobingen, Max Niemeyer, 1963, p. 163.

4. Hannah Arendt, La Vie de l'esprit, tr. fr. Lucienne Lotringer, Paris, PUF, 1981 tome 1, p.

237.

5. "Lettre au père", de Franz Kafka in Oeuvres complètes, "Bibliothèque de la Pléiade",

Gallimard, 1989, IV, p. 861.

6. Walter Benjamin-Gershom Scholem, Théologie et utopie. Correspondance 1933-1940, tr. fr.

Pierre Rusch et Didier Renault, Paris, Editions de l'éclat, 2011, p. 242.

7. Hannah Arendt, Vies politiques, Paris, Gallimard, 1974, p. 294. 
8. Walter Benjamin, Oeuvres, éd. Rainer Rochlitz, Paris, Gallimard, Folio essais, 2000, vol.

II, p. 453.

9. Walter Benjamin-Gershom Scholem, Théologie et utopie. Correspondance 1933-1940, op. cit., p. 157-158.

10. W. Benjamin-G. Scholem, Théologie et utopie, op. cit., p. 242.

11. Ibidem.

12. [Versión en español de José Ángel Valente.]

13. Walter Benjamin, Oeuvres, cit. vol. II, p. 270. 